University of Wollongong

Research Online

Faculty of Social Sciences - Papers (Archive) Faculty of Arts, Social Sciences \& Humanities

$1-1-2016$

\title{
Video feedback in CBT supervision: review and illustration of two specific techniques
}

Craig J. Gonsalvez

University Of Wollongong, craigg@uow.edu.au

Robert N. Brockman

University Of Technology Sydney

Hamish R. M Hill

University Of Wollongong, hrmh988@uowmail.edu.au

Follow this and additional works at: https://ro.uow.edu.au/sspapers

Part of the Education Commons, and the Social and Behavioral Sciences Commons

Research Online is the open access institutional repository for the University of Wollongong. For further information contact the UOW Library: research-pubs@uow.edu.au 


\title{
Video feedback in CBT supervision: review and illustration of two specific techniques
}

\author{
Abstract \\ There is now expert consensus that directly observing the work of trainee therapists vs. relying upon self- \\ report of sessions, is critical to providing the accurate feedback required to attain a range of \\ competencies. In spite of this expert consensus however, and the broadly positive attitudes towards video \\ review among supervisees, video feedback methods remain under-utilized in clinical supervision. This \\ paper outlines some of the weaknesses that affect feedback based solely on self-report methods, before \\ introducing some of the specific benefits that video feedback methods can offer the training and \\ supervision context. It is argued that video feedback methods fit seamlessly into CBT supervision \\ providing direct, accessible, effective, efficient and accurate observation of the learning situation, and \\ optimizing the chances for accurate self-reflections and planning further improvements in performance. \\ To demonstrate the utility of video feedback techniques to CBT supervision, two specific video feedback \\ techniques are introduced and described: the Give-me-5 technique and the I-spy technique. Case \\ examples of CBT supervision using the two techniques are provided and explored, and guidance as to the \\ supervision contexts in which each of the two techniques are suitable, individually, and in tandem, are \\ outlined. Finally, best practice guidelines for the use of video feedback techniques in supervision are \\ outlined.
}

\section{Keywords}

two, illustration, review, techniques, supervision:, specific, cbt, feedback, video

\section{Disciplines}

Education | Social and Behavioral Sciences

\section{Publication Details}

Gonsalvez, C. J., Brockman, R. N. \& Hill, H. R. M. (2016). Video feedback in CBT supervision: review and illustration of two specific techniques. The Cognitive Behaviour Therapist, 9 (e24), 1-15. 


\title{
Video feedback in CBT supervision: review and illustration of two specific techniques
}

\author{
Craig J. Gonsalvez ${ }^{1 *}$, Robert Brockman² and Hamish R. M. Hill ${ }^{3}$ \\ ${ }^{1}$ School of Social Sciences \& Psychology, University of Western Sydney, Australia \\ ${ }^{2}$ Graduate School of Health, University of Technology Sydney, Australia \\ ${ }^{3}$ School of Psychology, University of Wollongong, Australia
}

Received 4 April 2015; Accepted 26 June 2015

\begin{abstract}
There is now expert consensus that directly observing the work of trainee therapists $v s$. relying upon self-report of sessions, is critical to providing the accurate feedback required to attain a range of competencies. In spite of this expert consensus however, and the broadly positive attitudes towards video review among supervisees, video feedback methods remain under-utilized in clinical supervision. This paper outlines some of the weaknesses that affect feedback based solely on self-report methods, before introducing some of the specific benefits that video feedback methods can offer the training and supervision context. It is argued that video feedback methods fit seamlessly into CBT supervision providing direct, accessible, effective, efficient and accurate observation of the learning situation, and optimizing the chances for accurate self-reflections and planning further improvements in performance. To demonstrate the utility of video feedback techniques to CBT supervision, two specific video feedback techniques are introduced and described: the Give-me-5 technique and the I-spy technique. Case examples of CBT supervision using the two techniques are provided and explored, and guidance as to the supervision contexts in which each of the two techniques are suitable, individually, and in tandem, are outlined. Finally, best practice guidelines for the use of video feedback techniques in supervision are outlined.
\end{abstract}

Key words: CBT supervision, observational techniques in supervision, supervision methods, supervision techniques, video feedback

\section{Introduction}

The view that observational methods are critical for psychotherapy training and supervision is endorsed by experts espousing a range of therapeutic orientations, including CBT (Padesky, 1996a; Liese \& Beck, 1997; Roth \& Pilling, 2008; Milne et al. 2009) and non-CBT (Watkins, 1997; Bernard \& Goodyear, 2009) orientations. Increasingly, the requirement for competence in direct observation is being included in psychology training accreditation documents (e.g. Psychology Board of Australia, 2015) and supervisor competency frameworks

\footnotetext{
*Author for correspondence: Professor C. J. Gonsalvez, School of Social Sciences and Psychology, University of Western Sydney, Locked Bag 1797, Penrith 2751, Australia (email: c.gonsalvez@uws.edu.au)
} 
(e.g. Roth \& Pilling, 2008). Further, from a pedagogical point of view, observation is critical to the development of a wide range of important CBT competencies (Gonsalvez, 2014; Reiser, 2014). For instance, competency-based models of supervision differentiate between knowledge, skills, attitude-value, and relationship competencies (Falender \& Shafranske, 2004; Gonsalvez \& Calvert, 2014). Although having a supervisee present and discuss ongoing cases is a useful strategy to address knowledge and knowledge application competencies, the use of observational techniques (either by live monitoring through a one-way mirror or a video camera, or by delayed observation through a recorded DVD of a therapy session) is essential to inform supervisee reflection and supervisor feedback on skills, attitude-value and relationship competencies (Falender \& Shafranske, 2007; Gonsalvez \& Calvert, 2014; Gonsalvez \& Crowe, 2014). However, in spite of the scientific evidence favouring observation techniques, and preferences for observation among supervisees, video feedback methods remain an under-utilized supervision method (Gonsalvez et al. 2002; Townend et al. 2002; Milne \& Reiser, 2011).

\section{Limitations of case presentation and subjective report}

Supervision and individual reflection based on a supervisee's subjective report may be affected by a number of limitations. Supervisees may intentionally or unintentionally withhold information from supervisors (Muslin et al. 1981; Hantoot, 2000), or choose not to disclose important information, especially regarding the supervision relationship itself (Ladany et al. 1996; Gunn, 2007; Gunn \& Pistole, 2012). Lack of expertise, experiential knowledge, or the presence of processing biases may influence subjective report and significantly undermine the effectiveness of supervision practice based solely on self-report (Haggerty \& Hilsenroth, 2011). Further, an accurate appraisal of the client's presentation (client's verbal report and their non-verbal behaviours) is essential to an accurate case conceptualization of the client's problems, and the supervisor needs to observe the client's interactions (rather than rely on the supervisee's recall and interpretation of these behaviours) to ensure that the data informing the case conceptualization is indeed representative of the client's presentation (Gonsalvez, 2014; Gonsalvez \& Crowe, 2014). Our experience with training clinical psychologists over two decades suggests that the risk of flawed conceptualizations stemming from partial reporting of client data is particularly high early in practitioner training. Specifically, panic attacks may be mislabelled as general anxiety or agitation, and hypomanic presentations may be mislabelled as symptoms associated with attention-deficit disorders, because neither the client nor the novice therapist is sufficiently competent at making these important clinical differentiations. Finally, from a risk and evaluation perspective, self-assessment in the therapy context has been shown to have only low to moderate validity and reliability (Gordon, 1991). Accurate self-appraisal is an important competency (McManus et al. 2012) and is pivotal to important metacompetencies such as the reflective practitioner mindset (Gonsalvez \& Crowe, 2014). To monitor and foster growth in reflective practitioner competencies, the supervisor requires access to the supervisee's self-report and reflection and an observer's report and analyses (by the supervisor and/or others).

\section{Advantages of video techniques}

Compared with live-monitoring (e.g. through one-way mirrors), video recording and review is more convenient (obviates the need to synchronize diary appointments between supervisor, 
therapist and client), more accessible and cost efficient (a simple iPad can provide high fidelity recordings). Systematic video-based analysis and reflection in supervision promises to mitigate some of the drawbacks of subjective report, offering more direct reflection and feedback on practice, and potentially overcome known cognitive and memory biases. Video review enables a focus on process issues in therapy - in collaborative review with supervisors, video review can highlight strengths and weaknesses, opportunities, dilemmas and pivotal moments in therapy, and can be effectively employed both in individual and group supervision formats.

Further, recent advances in technology allow video upload by the supervisee and video review by the supervisor to be conducted online (Rousmaniere, 2014) or on custom-designed e-supervision applications (Deane et al. 2015). Finally, an important advantage of video techniques, compared with live observation methods, is that the video can be evaluated by multiple peers and supervisors, it can be replayed several times, and the review becomes accessible to the therapist after the session is actually conducted. The latter point is important because it has a bearing on the facilitation of metacompetencies such as reflective practice. Competent reflective practice has several components including reflection on action, reflecting in action, and reflection for action (Schön, 1995; Hallet, 1997). Reflection on action represents post-event (e.g. therapy session) evaluation and early practitioners may have to progress through the 'reflection-on-action' stage before they become capable of advanced skills such as 'reflection in action' (Gonsalvez \& Crowe, 2014).

\section{Video review techniques in CBT and supervision}

Video review techniques are increasingly becoming a core component in cognitive and behavioural treatments of several clinical problems. One of the first uses of video review within cognitive and behavioural approaches was with social-skills training programmes for people suffering from schizophrenia (e.g. Wallace et al. 1980). In a typical training session patients are asked to role-play interpersonal scenarios. The trainer then reviews the patient's performance and provides feedback; reinforcing more skilful social behaviors, and giving clear guidance and instruction to improve social performance (Wallace et al. 1980). In this context, video feedback is used to aid in the feedback process; providing an objective mirror of the social performance situation for analyses and playback.

Relatively recently, this paradigm has been extended to the training of communication skills in medical residents (Roter et al. 2004). Roter and colleagues (2004) argue, based on the available empirical evidence, that 'there is compelling evidence that experiential methods of communication skill instruction are superior to more traditionally didactic approaches'. Video feedback communication training led to significant improvements in domains of communication including reduced verbal dominance, increased use of open-ended questions, increased use of empathy, and increased partnership building and problem solving. The relevance of these findings to CBT supervision and training seem clear.

Perhaps the most famous use of video techniques has been with CBT for problems associated with social anxiety. In this context video techniques are used as a kind of behavioural experiment to challenge negative self-appraisal of performance and appearance in social interactions, and to update faulty negative self-imagery with more realistic and positive self-imagery (Clark, 2005). We argue that the situation with psychology supervisees is analogous in several ways to sufferers of social anxiety, making video techniques relevant 


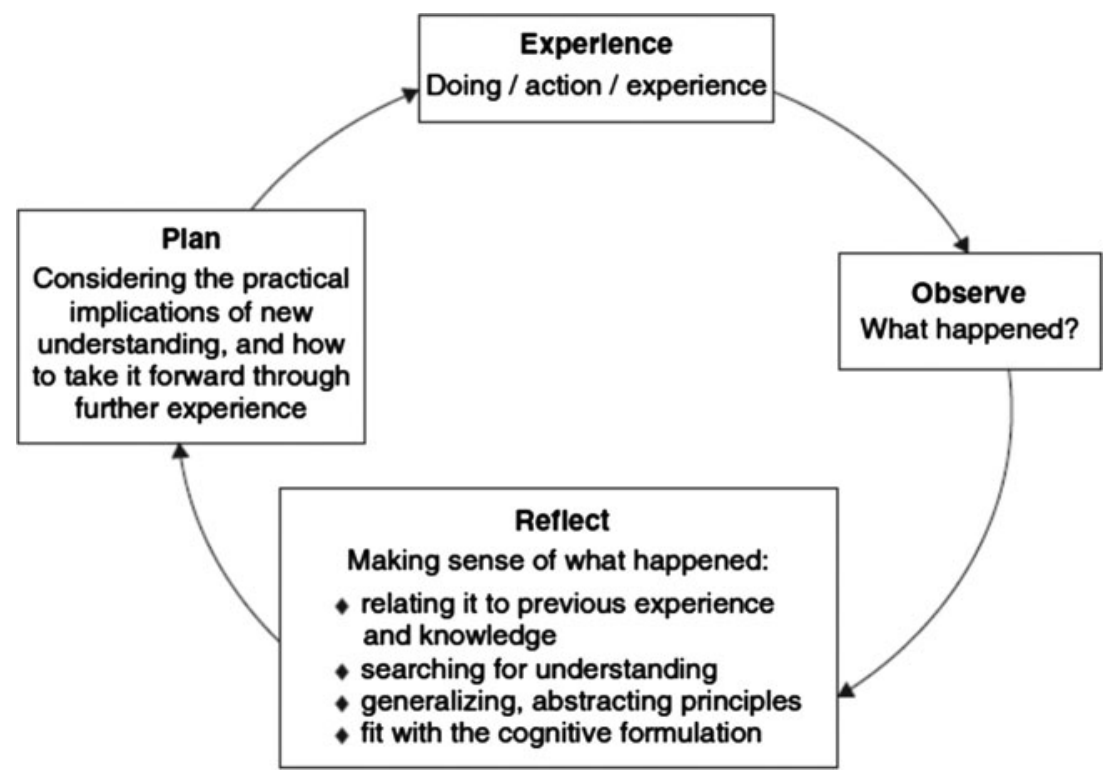

Fig. 1. Lewin/Kolb Experiential Learning Cycle [taken from Bennett-Levy et al. 2004 (fig. 1.2, p. 19), by permission of Oxford University Press].

to the training context. In particular, psychology training, like therapy, is in this context concerned with improving social/communication skills, reducing overwhelming anxiety, promoting accurate self-appraisals, and improving self-efficacy over time.

A useful theoretical framework for the use of video techniques within CBT is the Lewin/Kolb experiential learning cycle (Lewin, 1946; Kolb, 1984) (Fig. 1). This framework has been used extensively in CBT to assist in guiding 'experiential' learning in behaviour experiments (e.g. Bennett-Levy et al. 2004), and optimizing learning in clinical supervision and training (e.g. Milne, 2009).

Within this framework, video techniques appear highly relevant to the experiential learning cycle by providing a direct, accessible, replayable, and accurate observation of the learning situation. Such potential for accurate self-observation in the training context then optimizes the chances for successful self-reflections and planning further performance improvements. We use this framework in our analyses of the case material below.

\section{Rationale for the current paper}

It is paradoxical that, despite what we consider compelling justification for the use of observational methods, supervisors continue to neglect observation in favour of case presentation methods in their supervision (Townend et al. 2002; Gonsalvez \& McLeod, 2008). Further, supervision literature which documents, describes or evaluates specific video techniques remains limited (Huhra et al. 2008). Exceptions within the cognitive and behaviour therapy literature are James and colleagues' description of a method for post-hoc analysis of emotions and scaffolding skills in supervision (James et al. 2004), and Follette \& Callaghan's 
(1995) behaviour-analytic model of skills training. The microcounselling models of Ivey and colleagues are also well articulated (Daniels et al. 1997). Within the family therapy supervision literature, Taylor \& Gonzales (2005) outline a model based on Change Theory. Finally, one of the best-known models is the interpersonal process recall (IPR) method used in psychodynamic supervision (Kagan \& Kagan, 1997; Crews et al. 2005; Hill et al. 2015). We have employed the IPR technique in our own practice, but found somewhat variable results for CBT supervision, with sometimes disappointing results especially when supervisees are in early stages of their development. For reasons consistent with psychodynamic therapy and supervision, IPR provides the supervisee with little structure but significant control over what in the recorded section is reviewed and commented on, with the supervisor mostly playing a non-directive role. Applied to CB supervision, this can be productive when supervisees are insightful and have attained intermediate levels of self-awareness including recognition of what they do not know. In the case of CB practitioner training, where the focus was on the development of specific microskills (e.g. items on the Cognitive Therapy Rating Scale; Blackburn et al. 2001), there appears to be justification for the use of more structured techniques informed by skills-training pedagogies. The following sections will describe two specific video techniques that are useful for CB practitioner training. The video techniques were designed by the first author who trained novices acquiring CBT skills at the University of Wollongong, Australia, for two decades. Although we have not tested the outcomes of these techniques in formal research, the two techniques described in this paper are included in supervisor training workshops designed for the Australian Psychological Society (Gonsalvez \& Crowe, 2015). In data yet to be published, trainee supervisors who undertook these workshops rated the techniques positively in their post-workshop evaluations. Further research is needed to establish the effectiveness of the techniques, and could usefully randomize trainees to video and non-video review conditions and track progress as judged by validated measures such as the CTS-R (Blackburn et al. 2001).

\section{Video feedback: the Give-me-5 technique}

The Give-me-5 procedure involves supervisees and supervisors reviewing videos and identifying five (and no more than five) aspects of the session. The video technique emerged from evaluations by CBT supervisees, indicating that video feedback they received from their supervisors was frequently overwhelming and that, as novice therapists, they were typically unable to differentiate between major and minor aspects of the feedback. The Give-me-5 technique takes a 'wide-angle' lens approach of the emergent themes from the reviewed therapy segment/session. The aim is to identify highlights, salient issues and key patterns, rather than to focus on specific behaviours or moments of opportunity. Such a focus encourages a sense of balance between the many issues competing for attention within supervision sessions.

\section{Standard protocol}

The standard procedure has the following steps.

Step 1. The supervisee records a therapy session with his/her client, and chooses a 1520 minute uninterrupted segment that best captures what transpired in the session. 
Table 1. Supervisor's and supervisee's (Michael's) notes following Give-me-5 technique

\begin{tabular}{ll}
\hline Supervisee & Supervisor \\
\hline $\begin{array}{l}\text { (1) Poor progress with therapy (3'00 to 4'05) } \\
\text { (2) Unhelpful, fidgety and tapping behaviours by } \\
\text { myself during session (multiple instances) }\end{array}$ & $\begin{array}{l}\text { (1) Marginal progress with therapy (3'00 to 4'05) } \\
\text { (2) Lack of positive feedback for gains evidenced } \\
\text { in therapy (entire session) }\end{array}$ \\
$\begin{array}{ll}\text { (3) Client's non-compliance with homework } \\
\text { despite my best efforts (5'08 to 8'00) }\end{array}$ & $\begin{array}{l}\text { (3) Clear delivery of educational information but } \\
\text { overly didactic (e.g. 12'15 to 15'10) }\end{array}$ \\
$\begin{array}{ll}\text { (4) I demonstrated good psychoeducation skills } \\
\text { (e.g. 12'15 to 15'10) }\end{array}$ & $\begin{array}{l}\text { (4) Poor compliance with homework tasks, } \\
\text { possibly related to item 3, and therapist's } \\
\text { frustration to this (14'30) }\end{array}$ \\
$\begin{array}{ll}\text { (5) Therapist identified a range of automatic } \\
\text { thoughts (10'40,12'10,15'15) }\end{array}$ & $\begin{array}{l}\text { (5) Good CT skills in identifying and articulating } \\
\text { client's automatic thoughts (multiple } \\
\text { instances) }\end{array}$ \\
\hline
\end{tabular}

Step 2. The trainee reviews the tape, and using a form with three columns (time, observation, inferences/conclusions), analyses what transpired in the video segment. A summary that includes five key points are written down to discuss in supervision.

Step 3. The supervisor and supervisee review the video together (usually uninterrupted) during the supervision session (allowing the supervisee additional analyses of the material) before the supervisor writes down his/her five points.

Step 4. The supervisor and supervisee compare and discuss their respective comments and recommendations.

Step 5. If a skills-based competency is the focus of the discussion, role-play may be used to advance CB skills acquisition.

Step 6. The supervisor summarizes observations and implications, discusses the supervisee's evaluation of the technique, allows time for debriefing, and, if appropriate, negotiates a follow-up task.

\section{Give-me-5: case illustration}

Michael is enrolled in a Master of Clinical Psychology degree and is in supervision to advance his CBT competencies. Following good progress in therapy during the first few weeks with a new client, Michael reports that progress has stalled. There is unsatisfactory adherence to homework tasks and the client is reporting poor progress. Michael is somewhat concerned that the client may drop out, although the client has not directly articulated this. Following the supervisor's suggestion, Michael agrees to record the next therapy session and to analyse it with the Give-me-5 procedure. A summary of the five comments from both Michael and his supervisor are outlined in Table 1.

The results from the Give-me 5 technique are instructive (Table 1). It is apparent that there is less than perfect supervisor-supervisee agreement, a finding that is fairly typical early in CBT training. Michael's conclusion that there is unsatisfactory client progress derives from the client's report in session, 'not much has changed', whereas the supervisor's inference that there has been some progress derives from considering both the client's report and behavioural changes observed in the course of therapy (the client now engages in activities 
that he previously avoided). Michael appears over-concerned that his mannerisms (e.g. fidgetiness) might suggest to his client that he is a 'nervous person' and undermine his credibility (a fairly common concern among novice therapists). The supervisor disregards these behaviours because they are of minor significance to the effectiveness of the session, and expects these behaviours to reduce with experience. It is of note that the same data on the videotape concerning psychoeducation leads to somewhat different conclusions. Michael's judgement is guided by the fact that he presented the information clearly; the supervisor's judgement is informed by the recognition that effective psychoeducation is ensuring the client's accurate reception and unbiased acceptance of the information delivered. The supervisor uses the opportunity to discuss with Michael best-practice guidelines about psychoeducation, including the delivery of information in bite-sized chunks, using methods (e.g. visual/verbal) that are pertinent to the client, pacing the information, having the client summarize key elements of the information delivered, and evaluating how the new information changes the client's previously held beliefs and attitudes. Finally, it appears that Michael is evaluating his client's compliance with homework with the same rigorous standards that his own academic assignments are evaluated. Michael is also somewhat surprised that his frustration with his client's poor compliance with homework is more apparent on tape than he realized. Following discussion, Michael agrees that, in relation to the client's homework, a more supportive stance with generous positive feedback might work better, especially since the homework tasks involved unpleasant exposure therapy.

In summarizing the outcomes of the supervision session, Michael indicated that the Giveme-5 approach provided him with a bird's-eye view of the session and helped him regain a bigger-picture perspective of the intervention plan. He felt reassured there the therapy was resulting in slow but steady progress (although the client and Michael had so far failed to adequately acknowledge these gains), he gained a better understanding of the principles of psychoeducation and enhanced his skills to deliver psychoeducation effectively. He also 'learned a bit' about his attitudes towards himself (he could afford to be a bit more patient with himself), and towards his client (he could afford to be a lot more validating about the gains achieved by the client in exposure therapy).

\section{Protocol variations and other considerations}

The standard procedure is to approach the videotaped session with no a-priori assumptions. In certain circumstances, especially with novice therapists, broad guidelines about what to look for during the session may be useful (see Table 2).

In an overall sense, the simple Give-me-5 technique is versatile, powerful and can be used across theoretical persuasions. A personal meta-analysis of a series of Give-me-5 reports generated by the same individual but collected across multiple sessions is of particular value. Such a data series generated by the supervisee yields patterns of how they view their own therapy and how they make meaning of their client interactions: on what they choose to zoom in, and what they may ignore. The data series generated by the supervisor across supervisees provides an insight into the way supervisors view supervision and their supervisees: which competency domains and competency types are typically focused on, and which are given less salience. Comparing one's personal meta-analysis with patterns obtained by other supervisors may disclose unique strengths or potential blind-spots. For instance, the data from multiple Give-me-5 reports from one supervisor suggested very few 
Table 2. Guidelines for variations of the Give-me-5 method

Give-me-5 variations

(1) Five points pertaining to strengths (at least two) and developmental needs (at least two)

(2) Five stand-out issues: stuck points, turning points, surprises, or moments of insight

(3) Five themes to emerge during session/issues that appeared to most preoccupy the therapist's (at least two) and client's (at least two) minds during the session

(4) Five issues relating to specific supervision competencies including at least one issue from each of the competency types: knowledge, skills, relationships, and attitudes/values

(5) Client's appraisals of five issues: problem, self, others, therapist, therapy

(6) Five 'hot' topics: issues that provoked significant emotion in client and/or therapist

'mentions' pertaining to relationship competencies. Finally, when used in an interpersonally sensitive way, the technique can provide impactful feedback in group supervision. Normative trends emanating from Give-me-5 reports from several members within a group are powerful challenges to both self-aggrandizing and self-deprecatory evaluative biases.

\section{Video feedback: the I-spy technique}

I-spy (short for, 'I spy with my little eye ...') is a video review procedure which targets one specific microskill for special attention. Usually the competency targeted is a developmental need (e.g. the need for more frequent Socratic questions, validation responses, or summarizing responses). In situations where the supervisee is overly critical of themselves, one of the supervisee's strengths could be highlighted. The I-spy technique differs from Give-me-5 in many respects. If Give-me-5 is akin to using a 'wide-angle' lens to view therapy content and process; I-spy is a 'close-up' or 'zoom function'. Where Give-me-5 (as normally used) approaches the recorded session without any a priori assumptions, I-spy is hypothesis-driven. Give-me-5 is useful to get an overview of a supervisee's profile of strengths and needs, whereas I-spy is useful to work on a specific problem, or to acknowledge or build on a specific strength.

\section{Standard protocol}

The procedure includes the following steps.

Step 1. A microskill targeted for change is identified by the supervisor and/or supervisee (e.g. statements and rhetorical questions that are best expressed as reflective/Socratic questions)

Step 2. The supervisee identifies a 15-20 min uninterrupted segment that best captures what transpired in their CB therapy session, before proceeding to review the DVD in search of the targeted micro skill. Target occurrences are time tagged (e.g. 3 min $30 \mathrm{~s}$ ) and appropriate 'replacement' responses, if appropriate, are drafted. In circumstances where the supervisee recognizes an opportunity, but is unable to generate an appropriate replacement response, the target response is recorded. 
Step 3. The segment of the tape used in step 2 is jointly reviewed by both supervisor and supervisee, with the supervisor identifying additional opportunities for or suggesting appropriate replacement responses.

Step 4. If appropriate, the supervisor uses role-play to demonstrate skills.

Step 5. The supervisor summarizes observations and implications, discusses the supervisee's evaluation of the technique, allows time for debriefing, and negotiates a follow-up task.

\section{I-spy: case illustration}

Kim is undertaking formal clinical psychology training after several years of primarily humanistic counselling experience, and has commenced a new placement in a mood disorders clinic to train in CBT. The supervisor has reviewed two of her videotaped therapy sessions and has formed the opinion that Kim is skilled in using validation responses to empathize with the client's experience, but needs to further develop her skills in Socratic dialogue. Kim is happy to record and analyse her sessions and is confident that she is performing well. Kim views a video resource on Socratic dialogue (Padesky, 1996b) and uses the I-spy technique for her analyses. The specific task is for Kim to conduct therapy as she typically would, but to follow up important validation responses with one or more Socratic questions. Kim then reviews the DVD to tag times in the session when she manages to offer Socratic responses and others when she missed opportunities for a Socratic stance. Kim and her supervisor jointly review her recorded session, and the supervisor evaluates Kim's analysis using the I-spy protocol. The supervisor assists Kim in formulating Socratic questions as appropriate, highlighting the fact that rhetorical and clarifying questions do not qualify as Socratic questions.

In summarizing the outcomes of the supervision session (see Table 3), Kim indicates that the exercise greatly surprised her, and that, 'Socratic dialogue is hard!' The work associated with reviewing her therapy sessions and especially trying to come up with reflective Socratic questions was labour intensive but productive. She felt empowered that the technique could help overcome a need she now recognized. Kim also discloses that she was initially somewhat concerned that the Socratic questioning and more directive style of CBT would impair the therapeutic alliance when compared with her previous training, a reservation raised by a previous supervisor. However, the combination of affect-validation responses followed by integrative Socratic questions (Padesky, 1996b) reassures her that CBT techniques can foster alliance. The supervisor invites her to test out this new hypothesis/belief by evaluating alliance and effectiveness during subsequent sessions. Kim agrees to also do additional I-spy sessions to enhance her Socratic dialogue skills.

\section{Protocol variations and other considerations}

The I-spy technique is simple but versatile and effective, and can be applied across theoretical persuasions and in individual and group supervision formats. A range of microskills can be targeted systematically for change, with basic and advanced skills being tiered in a developmentally meaningful sequence. At its core, I-spy is a simple find-replace strategy, where the find-target is usually an unhelpful therapist behaviour or style (statement/rhetorical question, closed question) and the replacement response is the desired response (Socratic question, open question). For instance, in $\mathrm{CB}$ supervision, appropriate find-targets can 
Table 3. Supervisor and supervisee notes following I-spy technique. Note the discrepancy between supervisee and supervisor judgements of the same events

Supervisee

(1) Client expressed anxious thoughts but missed opportunity for downward arrow technique to get information on intermediate beliefs (4' 55 , 15 '22). I could have asked 'Wow, what would that say about you if that were true?'

(2) Client expressed cognitive distortions of underestimating ability to cope with adverse events - I validated fear but missed opportunity for exploring evidence for successful previous coping response (20'10). I could have said 'Have you faced anything like this before?'

(3) Other missed opportunities for collaborative questioning of cognitive distortions (13'45, 20'30). I could have completed a detective thinking sheet with the client

(4) I tried to use Socratic questions (15'33) but was it overly didactic?
Supervisor

(1) Missed opportunities for downward arrow (4'55, 10'10, 15'22 and 19'20)

(2) Missed challenging distortion opportunities at $10^{\prime} 45,30^{\prime} 33$ and 23'30

(3) Validation response was enough for client to question own thinking spontaneously (13'45, 25 '10)

(4) Excellent use of Socratic dialogue (15’33)

be 'didactic spells', advice-giving, telling clients what to think, unhelpful reassurance, drifting, excessive talking. Find-targets could also be client responses that indicate less than optimal engagement or unsatisfactory therapy progress, such as yes-but responses, passive compliance, disengaged behavior, subtle signs of negative affect such as resistance, disagreement, disapproval, or anger. In other circumstances, the target could be an opportunity for effective therapy behaviours, such as opportunities to articulate and clarify automatic thoughts, to validate salient affect, to provide positive feedback, to generate positive affect in the session, to provide capsule summaries, to initiate cognitive restructuring, to shift to nonverbal challenging strategies (e.g. imagery, behaviour rehearsal or behavioural experiments).

Because I-spy tends to focus more often on developmental needs, the risk is that supervision drifts into focusing disproportionately on therapist inadequacies rather than strengths. This risk can be mitigated by discriminating between two levels/types of the target response, an easier level that the supervisee is capable of demonstrating (attained competency) and a second that reflects a developmental need. For instance, the recorded therapy session could be searched for automatic thoughts that the therapist elicited and for occasions when more difficult and subtle automatic thoughts could have been clarified/articulated. In a similar way, the client's emotion targeted for validation could be varied at easy (obvious client affect) and advanced (subtle affect changes) levels. In group supervision, the I-spy technique yields a wealth of data in an efficient manner, especially if the video is accessible to all members electronically (e.g. through an e-supervision application). For instance, the Socratic questions generated by each member of the group could be shared within the group. Finally, as with the Give-me-5 technique, a personal meta-analysis of I-spy targets may help supervisors gain insight into their own preferences, biases, and supervisory styles. 


\section{Discussion}

In many ways, the two video techniques discussed are complementary, and may be used sequentially or in tandem, or combined with other supervision techniques (e.g. roleplay) to optimize outcomes at all stages of skills training: acquisition, consolidation and generalization. Although the two techniques are grounded in sound pedagogic principles, we acknowledge that we currently do not have empirical data demonstrating the effectiveness of the techniques. Further theoretical and empirical contributions are needed to determine which techniques may be most effective in a range of training and supervision contexts.

\section{Promoting supervisee well-being and perceived safety}

Adding video review to supervision can provoke significant anxiety among supervisees. This anxiety needs to be anticipated, planned for, and managed so that high arousal does not impede learning or performance. Video techniques also have the potential to cause harm if feedback is insensitive or punitive. The supervisor is in a unique position to be able to monitor the emotional wellbeing of supervisees in both individual and group supervision. In our experience, 'checking in' with supervisees through the session can promote feelings of safety, models a useful therapeutic technique, and builds awareness of supervisees' own emotional experiences. Using supervisory alliance measures such as the Supervisory Working Alliance Inventory (Efstation et al. 1990) or the ultra-brief Leeds Alliance in Supervision Scale (Wainwright, 2010) may also be helpful.

\section{Power dynamics, motivation and learning}

Close attention to power dynamics is crucial when implementing the use of video in supervision, particularly where the supervisee's own practice is being reviewed. Supervision approaches emphasising autonomy are preferred by most supervisees (Reichelt \& Skjerve, 2000), and the motivation and self-determination literature indicates that goal progress is enhanced when persons have autonomous, rather than controlled (externally imposed) motivations for their actions (Koestner et al. 2008). The challenge for supervisors is to weigh up potential advantages of structure and direction and to balance these with supervisee preferences for autonomy and discovery-based learning to ensure that supervision achieves the targeted competencies in a developmentally appropriate manner. Open discussion of power dynamics, negotiation of roles and interpersonal sensitivity are required of the supervisor in this context. In addressing these issues of power relations, it can also be helpful to model openness to feedback by engaging in reflective dialogue in supervision based on videos of the supervision process itself (Hill et al. 2015), or videos of the supervisor's own practice.

\section{Practice guidelines for video-based feedback}

Using video review in supervision is a skill which requires practice by both supervisees and supervisors. However, the rewards can be substantial for both supervisor and supervisee. Supervisees learn gradually to accurately reflect on, appraise, and then improve their competence as practitioners, a metacompetency that should serve them well during their long practitioner careers. In general, it is helpful to bear in mind that video-based feedback 
should follow best practice guidelines for formative feedback (Gonsalvez \& Crowe, 2015). These include: (i) focus on important aspects and ignore the trivial; (ii) feedback should be informative, specific, and functional; (iii) focus on patterns of responding rather than isolated instances; (iv) deliver feedback clearly and in an interpersonally sensitive manner; (v) state inadequacies and needs clearly; do not gloss over them; (vi) identify not only whether a therapist intervention/technique was helpful/unhelpful, but also what specifically contributed to this outcome (i.e. feedback mentions how a specific outcome was achieved); (vii) feedback includes a balanced coverage of strengths and needs, of validation and challenge; (viii) tailor feedback to the competency type. In other words, feedback differentiates between and appropriately addresses knowledge, skills, attitude, or relationship competencies; (ix) feedback is tailored to the developmental stage of trainee; (x) feedback is supervisee-centred, not supervisor-centred; (xi) where appropriate, the delivery of feedback is tailored to match emotional processing requirements (slower, check emotional responses to feedback, check accuracy of reception, check inferred attributions/predictions if appropriate); (xii) fedback is strategic: gives the supervisee tools that can be used in similar circumstances in the future, rather than the answer to a specific instance (teach a man to fish ....).

\section{Summary}

In the current paper, we have argued for a deliberate, systematic and more frequent use of observational methods, particularly video review and feedback, in CBT supervision and training. We cite strong support from expert consensus and competency-based pedagogies for observational techniques, and draw attention to the many limitations and biases that apply to case-presentation techniques. We describe and illustrate how two specific techniques, Give-me-5 and I-spy can be applied to advance CBT competency development in supervision.

\section{Declaration of Interest}

None.

\section{Recommended follow-up reading}

Gonsalvez CJ (2014). Establishing supervision goals and formalising a supervision agreement: a competency-based approach. In: Wiley Blackwell International Handbook of Clinical Supervision, 1st edn (ed. C. L. Watkins \& D. L. Milne), pp. 282-307. Chichester: Wiley.

Reiser RP (2014). Supervising cognitive and behavioural therapies. In: Wiley Blackwell International Handbook of Clinical Supervision, 1st edn (ed. C. L. Watkins \& D. L. Milne), pp. 493-517. Chichester: Wiley.

\section{References}

Bernard JM, Goodyear RK (2009). Fundamentals of Clinical Supervision, 4th edn. Upper Saddle River: Pearson Education. 
Bennett-Levy J, Butler G, Fennell M, Hackmann A, Mueller M, Westbrook D (eds). (2004). Oxford Guide to Behavioural Experiments in Cognitive Therapy. New York: Oxford University Press.

Blackburn I-M, James IA, Milne DL, Baker C, Standart S, Garland A, Reichelt FK (2001). The revised Cognitive Therapy Scale (CTS-R): psychometric properties. Behavioural \& Cognitive Psychotherapy 29, 431-446.

Clark DM (2005). A cognitive perspective on social phobia. In: The Essential Handbook of Social Anxiety for Clinicians (ed. W. R. Crozier \& L. E. Alden), pp 193-218. Chichester: Wiley.

Crews J, Smith MR, Smaby MH, Maddux CD, Torres-Rivera E, Casey JA, Urbani S (2005). Selfmonitoring and counseling skills: skill-based versus interpersonal process recall training. Journal of Counseling and Development 83, 78-85.

Daniels TG, Rigazio-DiGilio SA, Ivey AE (1997). Microcounseling: a training and supervision paradigm for the helping professions. In: Handbook of Psychotherapy Supervision (ed. C. E. Watkins Jr.), pp. 277-295. New York: Wiley.

Deane FP, Gonsalvez C, Blackman R, Saffioti D, Andresen R (2015). Issues in the development of e-supervision in professional psychology: a review. Australian Psychologist 50, 241-247.

Efstation JF, Patton MJ, Kardash CM (1990). Measuring the working alliance in counselor supervision. Journal of Counseling Psychology 37, 322-329

Falender CA, Shafranske EP (2004). Clinical Supervision: A Competency-based Approach pp. 37-58. Washington, DC: American Psychological Association.

Falender CA, Shafranske EP (2007). Competence in competency-based supervision practice: construct and application. Professional Psychology: Research and Practice 38, 232-240.

Follette WC, Callaghan GM (1995). Do as I do, not as I say: a behavior-analytic approach to supervision. Professional Psychology - Research \& Practice 26, 413-421.

Gonsalvez CJ (2014). Establishing supervision goals and formalising a supervision agreement: a competency-based approach. In: Wiley Blackwell International Handbook of Clinical Supervision, 1 st edn (ed. C. L. Watkins \& D. L. Milne), pp. 282-307. Chichester: Wiley.

Gonsalvez CJ, Calvert F (2014). Competency-based models of supervision: principles and applications, promises and challenges. Australian Psychologist 49, 200-208.

Gonsalvez CJ, Crowe T (2014). Evaluation of psychology practitioner competence in clinical supervision. American Journal of Psychotherapy 68, 177-193.

Gonsalvez CJ, Crowe T (2015). Board approved supervisor training Part 2: Skills based training workshop. Supervisor Training Manual. Melbourne: Australian Psychological Society.

Gonsalvez CJ, McLeod HJ (2008). Toward the science-informed practice of clinical supervision: the Australian Context. Australian Psychologist 43, 79-87.

Gonsalvez CJ, Oades LG, Freestone J (2002). The objectives approach to clinical supervision: Towards integration and empirical evaluation. Australian Psychologist 37, 68-77.

Gordon MJ (1991). A review of the validity and accuracy of self-assessments in health professions training. Academic Medicine 66, 762-769.

Gunn JE (2007). Supervisee attachment: relationship to the alliance and disclosure in supervision (Doctoral disseration). Available from ProQuest Dissertations and Theses database (ID No. 304839374).

Gunn JE, Pistole M (2012). Trainee supervisor attachment: explaining the alliance and disclosure in supervision. Training \& Education in Professional Psychology 6, 229-237.

Haggerty G, Hilsenroth MJ (2011). The use of video in psychotherapy supervision. British Journal of Psychotherapy 27, 193-210.

Hallett CE (1997). Learning through reflection in the community: the relevance of Schon's theories of coaching to nursing education. International Journal of Nursing Studies 34, 103-110.

Hantoot MS (2000). Lying in psychotherapy supervision: why residents say one thing and do another. Academic Psychiatry 24, 179-187. 
Hill HRM, Crowe TC, Gonsalvez CJ (2015). Reflective dialogue in clinical supervision: a pilot study involving collaborative review of supervision videos. Psychotherapy Research. Published online: 6 February 2015. doi:http://dx.doi.org/10.1080/10503307.2014.996795.

Huhra RL, Yamokokski-Maynhart CA, Prieto LR (2008). Reviewing videotape in supervision: a developmental approach. Journal of Counseling \& Development 86, 412-418.

James IA, Allen K, Collerton D (2004). A post-hoc analysis of emotions in supervision: a new methodology for examining process features. Behavioural and Cognitive Psychotherapy 32, 507513.

Kagan H, Kagan N (1997). Interpersonal process recall: influencing human interaction. In: Handbook of Psychotherapy Supervision (ed. C. E. Watkins Jr.), pp. 421-446. New York: Wiley.

Koestner R, Otis N, Powers TA, Pelletier L, Gagnon H (2008). Autonomous motivation, controlled motivation, and goal progress. Journal of Personality 76, 1201-1229.

Kolb D (1984). Experiential Learning: Experience as the Source of Learning and Development. New Jersey: Prentice Hall, Englewood Cliffs.

Ladany N, Hill CE, Corbett MM, Nutt EA (1996). Nature, extent, and importance of what psychotherapy trainees do not disclose to their supervisors. Journal of Counseling Psychology 43, $10-24$.

Lewin K (1946). Action research and minority problems. Journal of Social Issues 2, 34-46.

Liese SB, Beck JS (1997). Cognitive therapy supervision. In: Handbook of Psychotherapy Supervision (ed. C. E. Watkins), pp. 114-133. New York: Wiley.

McManus F, Rakovshik S, Kennerley H, Fennell M, Westbrook D (2012). An investigation of the accuracy of therapists' self-assessment of cognitive-behaviour therapy skills. British Journal of Clinical Psychology 51, 292-306.

Milne D (2009). Evidence-based Clinical Supervision. Chichester: BPS Blackwell.

Milne DL, Leck C, Choudhrie NZ (2009). Collusion in clinical supervision: literature review and case study in self-reflection. The Cognitive Behaviour Therapist 2, 106-114.

Milne DL, Reiser R (2011). Observing competence in CBT supervision: a systematic review of the available instruments. The Cognitive Behaviour Therapist 4, 89-100.

Muslin HL, Thurnblad RJ, Meschel G (1981). The fate of the clinical interview: an observational study. American Journal of Psychiatry 138, 822-825.

Padesky CA (1996a). Developing cognitive psychotherapist competency: teaching and supervision models. In: Frontiers of Cognitive Therapy (ed. P. M. Salkovskis), pp. 266-292. New York: Guilford.

Padesky CA (1996b). Guided discovery using socratic dialogue. DVD Resource (http://www. padesky.com).

Psychology Board of Australia (2015). Guidelines for area of practice endorsement (http://www. psychologyboard.gov.au/Endorsement/Registrar-program.aspx).

Reichelt S, Skjerve J (2000). Supervision of inexperienced therapists: a qualitative analysis. The Clinical Supervisor 19, 25-43.

Reiser RP (2014). Supervising cognitive and behavioural therapies. In: Wiley Blackwell International Handbook of Clinical Supervision, 1st edn (ed. C. L. Watkins \& D. L. Milne), pp. 493-517. Chichester: Wiley.

Roter DL, Larson S, Shinitzky H, Chernoff R, Serwint JR, Adamo G, Wissow L (2004). Use of an innovative video feedback technique to enhance communication skills training. Medical Education 38, 145-157.

Roth AD, Pilling S (2008). A competence framework for the supervision of psychological therapies (http://www.ucl.ac.uk/clinical-psychology/core/competence_frameworks.htm).

Rousmaniere T (2014). Using technology to enhance clinical supervision and training. Wiley-Blackwell International Handbook of Clinical Supervision. Chichester: Wiley Publishers.

Schön DA (1995). The Reflective Practitioner: How Professionals Think in Action. Aldershot: Arena. 
Taylor RJ, Gonzales F (2005). Communication flow and change theory within a family therapy supervision model. Contemporary Family Therapy: An International Journal 27, 163-176.

Townend M, Iannetta L, Freeston MH (2002). Clinical supervision in practice: a survey of UK cognitive behavioural psychotherapists accredited by the BABCP. Behavioural and Cognitive Psychotherapy 30, 485-500.

Wainwright NA (2010). The development of the Leeds Alliance in Supervision Scale (LASS): A brief sessional measure of the supervisory alliance (unpublished doctoral thesis). University of Leeds (http://etheses.whiterose.ac.uk/id/eprint/1118).

Wallace CJ, Nelson CJ, Liberman RP, Aitchison RA, Lukoff D, Elder JP, Ferris C (1980). A review and critique of social skills training with schizophrenic patients. Schizophrenia Bulletin 6, 42.

Watkins Jr. CE (1997). Reflections on contemporary psychotherapy practice, research, and training. Journal of Contemporary Psychotherapy 27, 5-22.

\section{Learning objectives}

(1) Articulate the rationale for the supervisor's use of observational methods in supervision and commence using observation regularly in own supervision.

(2) Articulate the procedures, applications, and advantages of using the Give-me-5 and I-spy video techniques in supervision.

(3) Correctly apply the two video techniques in one's own supervisory practice.

(4) Articulate best-practice guidelines for formative feedback in supervision and adhere to these guidelines in own supervision. 